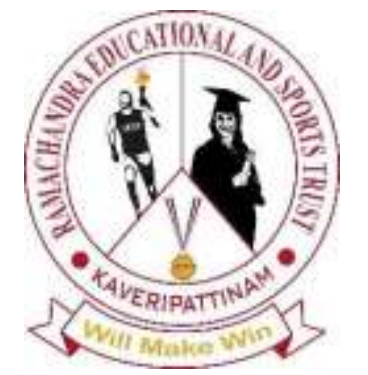

Recent trends in Management and Commerce

Vol: 2(3), 2021

REST Publisher

ISBN: 978-81-936097-6-7

Website: http://restpublisher.com/book-series/rmc/

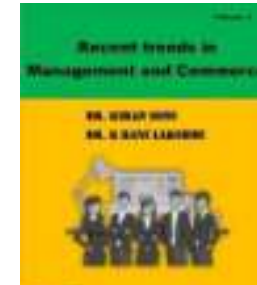

(1)

\title{
A Study on Multi-Objective Optimization on the basis of Ratio Analysis
}

\author{
Vimala Saravanan, M. Ramachandran, T. Vennila, G. Mathivanan \\ REST Labs, Kveripattinam, Krishnagiri, Tamil Nadu, India. \\ Email: vimala@restlabs.in
}

\begin{abstract}
In most developing countries riveting, offset forging and punching operations are done using manual hammer technique; the purpose of this study is therefore to produce AHM at affordable prices using material selection methods useful in design and fabrication processes. In this study, a vague multipurpose optimization model based on ratio analysis (ambiguous MOORA) is used to evaluate the supplier's overall performance. In fact, suppliers face risks such as natural disasters or political change. Therefore, Failure Method and Impact Analysis (FMEA) is implemented to assess a supplier's risks. Furthermore, a novel multi-objective mathematical model was developed to simultaneously consider the stability and order of the supplier. Therefore, in order to survive in a global competitive environment, it is imperative to implement the appropriate ERP system. However, choosing the wrong ERP system can affect the overall performance of the manufacturing company. Due to the limitations in the available resources, the complexity of the ERP systems and the diversity of alternatives, it is often difficult to choose. And install the most suitable ERP system for a manufacturing company.
\end{abstract}

\section{Introduction}

Credit rating is a multifaceted decision-making problem involving conflicting criteria. Basically, institutional based financial ratios are used to solve this problem. A bank or financial institution may accept one or more loan applications from companies. Therefore, financial institutions allocate a limited budget to the lending process. Digitalization is deeply changing the way humans interact with the world around them, as witnessed in the daily lives of people ranging from mobile phones to smart wearable devices. The impact of these new technological solutions is affecting all industries. Supply chains are no exception. However, the distribution chains of digital products and services are not digital. Manufacturing, Distribution and Operations Most are done independently in traditional ways, including geographically scattered physical facilities and connections for switching objects between these facilities. The help of an effective financial system, the main reason for this situation is, it is possible to provide a link between claimants and suppliers. This situation contributes to the amount of investment this leads to a decline in the unemployment rate in the country. Even 75 years after India's independence, the country is still ignorant of social and financial plans, Overpopulation, rural backwardness, malnutrition, unemployment, illiteracy, facing problems such as family breakdown and short life. Standards. Comprehensive feedback on quality of life with the aim of meeting the special needs of the marginalized group. There is no significant study yet on Supply chain practices and its performance appraisal and benchmarking are generally evolving In countries and in India.

\section{MOORA Method}

Six examples of solving multi-reference decision-making problems in a real-time production environment are considered to demonstrate the compatibility and effectiveness of the MOORA method. Select this NTM process Although the problem is solved using the MOORA method, the ultrasonic machine is considered to be the most suitable NTM process for creating cylinder standard with holes in ceramic materials. Of beneficial properties Extensive calculations are shown where the total number is equal to the ineffective properties, so some rating values are positive and some are negative. From this table, the laser the beam machine is the second best choice, and the performance of the water jet engine and the abrasive jet machine are almost identical. From above Discussions may conclude that for six decision-making problems, the MOORA method meets all the recommended conditions, and therefore, this method is very robust in different production contexts. The method is based on simple ratio analysis only; this is a very small scale Includes mathematical calculation, which can be very useful and helpful for decision makers who do not have a strong background in mathematics. Also, the calculation time of the MOORA method is apparently shorter. Similarly, other MODM methods require separate software to work, but the MOORA method can work in MS Excel. For this reason, various The MOORA methods is very consistent with decisionmaking issues. Therefore, the selection process for finding the most satisfactory ERP software among the possible alternatives in the market, decision making (MCDM) should be achieved using one of several proven criteria. By adopting an MCDM-based approach, the decision maker, T4 he selection decision can be strengthened on the basis of consistency, accountability and honesty, which are always considered a prerequisite for complex and risky decisions. In this study, to select the best ERP systems for two manufacturing companies, the use of ambiguous multi-purpose optimization based on 

with inaccurate and ambiguous evaluation data. It has also proven to be a simple, easy to understand and accurate tool for judging. Evaluation and selection results using the WEDM process parameter the integrated application of the AHP / MOORA method is given in this table, and all 27 alternatives are based on a weighted rating Are done. Depending on the test design, the best multi-performance features of the WEDM process in test or alternative number 1927 tests Provides is clearly observed. Proposing the IVIFN-MOORA method using score functions and materials for mushroom cultivation in Vietnam Use it to select. The Moore method, which uses scoring operations, applies to select materials for mushroom cultivation in Vietnam.

\section{Optimization}

Therefore, the most satisfactory ERP software among the possible alternatives in the market should be a selection process for detection using one of the many proven criteria for decision making (MCDM). MCDM-based approach By adhering to, the decision maker can strengthen the selection decision based on consistency, accountability and honesty, which are always considered a prerequisite for complex and risky decisions. Can. In this study, the use of ambiguous multi-purpose optimization based on the ratio analysis (MOORA) method was proposed to select the best ERP systems for the two manufacturing companies. The ambiguous MOORA method has also proven to be a simple, an easy and accurate tool to solve decision-making problems with inaccurate and ambiguous evaluation data. Evaluation and selection results of the WEDM process parameter Integrated application of the AHP / MOORA method Is given in this table, and all 27 substitutions are made on the basis of weight estimation. Test design, test or Alternative No. 1927 Tests It is clearly stated that it provides the best multi-performance features of the process with respect to WEDM. Score Propose the IVIFNMOORA method using functions and use it to select materials for mushroom cultivation in Vietnam. Mushrooms in Vietnam the Moore method, which uses scoring operations, applies to selecting materials for cultivation. Besides, DE is a vigorous quest calculation for tackling enhancement issues at persistent stretches. By and large, The DE calculation is utilized to conquer a significant blemish in the hereditary calculation of neighborhood search. The means of this half and half calculation are depicted in the accompanying. The MOORA technique was introduced one of the multi-reason improvement strategies for viably taking care of intricate dynamic issues. This strategy tries to choose the best option by considering a bunch of standards that for the most part struggle. At the end of the day, this technique investigates both positive and negative standards at the same time. Mentioned Taking into account the advantages of each method, the score is based on Z-number theory (Z-MOORA) and ambiguous best-bad mode (FBWM) and extended FMEA approach using multi-purpose optimization. In the proposed approach, the first step is FMEA After detecting failures based on the technique; FBWM is used to assign weight to SOD factors in the second phase of the three-phase approach. In fact, the FBWM system is different for SOD factors, such as inability to assign weights Is used to solve and avoid uncertainty in the comparison process as a result of conflicting opinions of experts in conventional FMEA technique. Its features. Improvement in terms of the rate system, beneficial attributes with the default performance of the event (Upgrade) is added and subtracted (reduced) from useless attributes, which can be expressed by the following expression: These results are more complex. Decision makers are based on conflicting criteria, with a wide range of alternatives to be evaluated. In this paper, the use of multi-objective optimization, based on a proportional analysis approach, is explored to solve such decisionmaking problems. Further reference point is the effectiveness of the approach Tested for decision-making issues to be considered. Besides, DE is a powerful quest calculation for tackling streamlining issues at nonstop stretches. By and large, the DE calculation is the quality for neighborhood look through Used to conquer a significant blemish in the calculation. The means of this cross breed calculation are portrayed in the accompanying. The MOORA technique was introduced as one of the multi-reason advancement strategies for viably settling complex choice Creates issues. This technique looks to choose the best option by considering a bunch of rules that for the most part struggle. As such, this strategy is at the same time sure and investigates negative standards. Taking into account the Advantages of each of the methods mentioned, the score is Znumber theory (Z-MOORA) and ambiguous best-bad mode (FBWM) and multipurpose Based on an extended FMEA approach using optimization. In the proposed approach, after detecting failures based on the FMEA technique in the first phase, the three-phase FBWM is used to assign weight to SOD factors in the second phase of the approach. In fact, like the inability to assign different weights to SOD factors The FBWM method is used to solve problems. To avoid uncertainty in the comparison process as a result of possible conflicting opinions of experts on conventional FMEA technique. Its features. Based on the ratio method approach of the MOORA method To improve, the beneficial attributes (enhancement) will be added to the default performance in the event and subtracted (minimized) from the useless attributes expressed by the following expression: Most of these results Are complex. Decision makers need to evaluate a wide range of alternatives based on conflicting criteria. This The paper is based on a proportional analysis approach, with multiple objectives. Making such a decision the application of optimization to solve problems is explored. Note on further decision-making issues under consideration the effectiveness of the point approach is tested.

\section{Taguchi Method}

The accompanying contextual analysis outlines the utilization of the MOORA-based Taguchi technique. This review was directed to work on the nature of the clothes washer model for the clothes washer producer in Turkey. Being used, above all else the nature of a clothes washer and the variables that decide their not really settled. Accordingly, these variables and their connections were estimated utilizing the MOORA-based Taguchi model created in this review. At last the ideal degrees of not really set in stone with the arrangement of the example. For the situation study, alongside the Taguchi strategy, a few properties, for example, GRA, TOPSIS and VIKOR dynamic techniques are utilized in the streamlining system and their answer execution compared with the proposed model. The outcomes show that no technique is conceivable, which would prompt preferable improvement over the MOORA-based Taguchi strategy. Subtleties of contextual investigation models and application steps are given in after segments. To accomplish the best surface quality in instruments and parts; Most of the 
ideal cycle boundary framework is a significant component. Machine control boundaries can be further developed utilizing an assortment of techniques to work on quality. The Taguchi technique is generally utilized in exploratory plan, for the most part in assembling applications. Turning, crushing, electro release it permits to work on the boundaries in the machine by machine, wire cutting EDM, welding, crushing and so on this general expense update is insignificant, time accomplished through various preliminaries Saves. One more benefit of the Takuchi technique is the set number of tests needed by the Orthogonal Array (OA) plan. Are required. Notwithstanding, the issue of multipurpose advancement can't be tackled by the customary Taguchi technique. To stay away from this inadequacy, it is important to transform various targets into a general objective capacity called the general quality code. Along these lines, multi-objective improvement is an issue, and on the off chance that the true streamlining is changed to intricate, the conventional Dutch strategy is the ideal outcome. Simple to use for rating. In a multi-objective enhancement arrangement, measure the overall significance of the entropy of every standard. Can be determined utilizing criticism. In data hypothesis, entropy is a proportion of how sporadic a framework is. Will utilize the entropy idea when estimating weight, a trademark with high entropy has an enormous number of result boundaries. This trademark significantly affects the result boundary.

\section{Decision Making}

The MOORA approach refers to multidisciplinary progress based on "ratio analysis, reference point approach and whole multiplication" This approach is mainly used for multi-attribute optimization. This approach was proposed by a researcher who used MOORA in different ways. Of the mode of production MOORA is used to make decisions in the life cycle. Used in the MOORA supply chain for risk assessment. Used as a multipurpose decision maker for the MOORA port. Welding process The MOORA method was used to improve the parameters. Selected material based on the MOORA method. The MOORA system is in the context of production decision making Used. MULTI MOORA is used to buy property with a bank loan. MULTI MOORA is used for project management economy. (2010) used MOORA for regional development in a country. Facilities to test the field, MOORA was used with ratio and reference point. It is difficult to analyze the many transactions involved in decision making, especially in times of uncertainty due to environmental considerations. Process time, complex procedures or incorrect information channels Causing problems in selecting contractors. Contractor rating is recognized as a particularly complex task due to ambiguity and rating there are no general rules for the process. Several criteria for MOORA and WASPAS in supplier selection from ranking results, given It is clear that Supplier I would be the second best choice for industrial use given the conditions while Supplier B would be the second best choice. Mentioning E is a bad choice. In today's world of technology, it is difficult to estimate the potential CNC machine tool out of the myriad options available Creating is a key to improving the effective use of resources, increasing productivity and improving system flexibility Has become a factor. One of the most viable alternatives is the multi-dimensional decision making (MCDM) problem.

\section{Multiple Objectives}

Making multiple objective decisions means that different objectives must be optimized to face their own units and different alternative solutions. A table (a group) of multiple goals, criteria (Weak form of objectives) or collects source data vertically through horizontal alternative solutions such as indicators and schemes. There are two different methods called MOORA, namely the rate system and the reference point starting from the obtained ratios. Attitude, trying to improve the content. However, the calculation of regional income is not sufficient. Individual RI may be a dependent. Moreover, regional income is the economy of the welfare state is a common expression. In the welfare economy, every individual is well aware of material wealth, health, education, and all kinds of security and safety should have known. Environment. Therefore, several objectives must be accomplished. Many goals, realized simultaneously, measure well-being. Table 1 The 16 data in the attributes, if improved, will become the maximum or minimum objectives. At that point, the MOORA method will do work. Considering only a limited number of goals, of several goals Organization, in which all unrelated motives are considered. The same is true for a limited number of alternatives. Selection and importance of goals and the method of many nonsubjective goals is much stronger than this method of applying subjective evaluations to normalization.

\section{Ratio Analysis}

Making multiple objective decisions means that different objectives must be optimized to face their own units and different alternative solutions. A table (a group) of multiple goals, criteria (Weak form of objectives) or collects source data vertically through horizontal alternative solutions such as indicators and schemes. There are two different methods called MOORA, namely the rate system and the reference point starting from the obtained ratios. Attitude, trying to improve the content. However, the calculation of regional income is not sufficient. Individual RI may be a dependent. Moreover, regional income is the welfare state economy Is a common expression. In the welfare economy every individual should be well aware of material wealth, health, education, all kinds of security and environment. Therefore, many objectives are accomplished to. Multiple goals simultaneously realized and measured well-being. 16 data attributes in Table 1 and, if improved, the maximum or Will also become minimal objectives. At that point, the MOORA method will work. Considering only a limited number of goals, a system of multiple goals, all of these have unrelated objectives are considered. The same is true for a limited number of alternatives. Many non-subjective than this method of applying subjective assessments to the selection and significance and normalization of goals the pattern of goals is very strong. Making multiple objective decisions means that different objectives must be optimized to face their own units and different alternative solutions. In this study the proposed end support model, such as a table (a group), criteria (weak form of objectives) or indicators and plans perpendicular to multiple objectives, is a vague multi-point perspective. Weight Ratio Analysis (ambiguous voice) and Ratio analysis (ambiguous MOORA) method. Be efficient with optimization. In summary, the contributions of this article are as follows. Multi-Objective Optimization was developed based on the Multi-Objective Optimization based on the MOORA approach (MOORA), which has two Consists of components, ratio system approach and reference point approach. The IVIF 
MOORA system configures complex systems with conflicting criteria MDCM method for upgrading. And focuses on selection and ranking. Of ratio analysis (MOORA) based multi-objective optimization, mathematically straightforward for optimization problems and compared to GRA Provides easy-to-apply process. Furthermore, MOORA takes into account the comparative weights of mathematically measured answers. MOORA was first developed for economy and then invented for use To determine the optimal production processes and to select the quantity of materials in a product design. In this study, the ambiguous analysis hierarchical process (FAHP) and ratio analysis (MOORA) We have selected seven IITs for performance evaluation under a multi-criterion analysis environment, using an integrated approach based on method-based multi-objective optimization. The decision-making channel of cognitive radio technology Solution to routine The purpose of this article is to present the problem of decision making using Multi-Objective Optimization (MOORA) based on nonfunctional ratio analysis (MOORA). Using the MOORA algorithm, results with moderate criteria can top the list of available choices. Of another channel it is not really possible to use other similar decision-making methods with linear weight objectives. Then, multipurpose optimization based on ratio analysis (MOORA) is easy to understand and evaluated in determining the degree of flexibility can be subjectively separated from the process. Multi-Objective Optimization (MOORA) is a multipurpose decision support system based on a ratio analysis that combines two or more attributes or criteria simultaneously. Even if they are conflicting criteria, improving. If a criterion generates a positive value or is in the form of benefits, the criterion will have a positive value; On the other hand, if the criterion cost is generated, the criterion will have a negative value. MOORA refers to a ratio system in which the response of each answer for a particular purpose is compared with the class, which is the representation of all alternatives related to the objective.

\section{Conclusion}

And the relevance of the MOORA method to solving multiple decision-making problems in the real-world production environment the following six illustrative examples are considered to demonstrate effectiveness as well. This is the NTM process Although the selection problem is solved using the MOORA method, the ultrasonic machine is in ceramic materials The cylinder with holes is considered to be the most suitable NTM process for creating standard. Besides, DE is about optimization issues at regular intervals Is a powerful quest calculation for settling. As a rule, the DE calculation is utilized to defeat a significant deficiency in the hereditary calculation of nearby inquiry. The means of this half breed calculation are portrayed in the accompanying. The following case study illustrates the use of the MOORA-based Taguchi method. Washing in Turkey this study was conducted to improve the quality of the washing machine model for the machine manufacturer. The MOORA approach refers to multidisciplinary progress based on "ratio analysis, reference point approach and whole multiplication" (MULTIMOORA). This approach is mainly used for multi-attribute optimization. MOORA in different ways this approach was proposed by a researcher who used. MOORA is used to make decisions in the life cycle of a production system. MOORA was used in the supply chain for risk assessment. Many objective decisions are made with different objectives having their own units and different alternative solutions Means to be optimal to face. A table (a group) collects source data vertically through multiple goals, criteria (weak form of objectives) or horizontal alternative solutions such as indicators and plans. Various decision-making issues often encountered in the real-time production environment To solve, explore the application of multi-purpose optimization based on the MOORA method. Six issues in decision making have been resolved and the results obtained have proven applicability.

\section{References}

1. Chakraborty, Shankar. "Applications of the MOORA method for decision making in manufacturing environment." The International Journal of Advanced Manufacturing Technology 54, no. 9 (2011): 1155-1166.

2. Gadakh, V. S., Vilas Baburao Shinde, and N. S. Khemnar. "Optimization of welding process parameters using MOORA method." The International Journal of Advanced Manufacturing Technology 69, no. 9-12 (2013): 20312039.

3. Karande, Prasad, and Shankar Chakraborty. "A Fuzzy-MOORA approach for ERP system selection." Decision Science Letters 1, no. 1 (2012): 11-21.

4. Patel, Jaksan D., and Kalpesh D. Maniya. "Application of AHP/MOORA method to select wire cut electrical discharge machining process parameter to cut EN31 alloys steel with brasswire." Materials Today: Proceedings 2, no. 4-5 (2015): 2496-2503.

5. Thao, Nguyen Xuan. "MOORA models based on new score function of interval-valued intuitionistic sets and apply to select materials for mushroom cultivation." Neural Computing and Applications (2021): 1-11.

6. Muniappan, A., Justin Arokiya Raj, V. Jayakumar, R. Shanmuga Prakash, and R. Sathyaraj. "Optimization of WEDM process parameters using standard deviation and MOORA method." In IOP conference series: materials science and engineering, vol. 402, no. 1, p. 012139. IOP Publishing, 2018.

7. Liang, Zong-Liang, Tae-Jong Yun, Won-Bin Oh, Bo-Ram Lee, and Ill-Soo Kim. "A study on MOORA-based taguchi method for optimization in automated GMA welding process." Materials Today: Proceedings 22 (2020): 1778-1785.

8. Dabbagh, Rahim, and Samuel Yousefi. "A hybrid decision-making approach based on FCM and MOORA for occupational health and safety risk analysis." Journal of safety research 71 (2019): 111-123.

9. Ghoushchi, Saeid Jafarzadeh, Samuel Yousefi, and Mohammad Khazaeili. "An extended FMEA approach based on the Z-MOORA and fuzzy BWM for prioritization of failures." Applied Soft Computing 81 (2019): 105505.

10. Sarkar, Asis, S. C. Panja, Dibyendu Das, and Bijon Sarkar. "Developing an efficient decision support system for non-traditional machine selection: an application of MOORA and MOOSRA." Production \& Manufacturing Research 3, no. 1 (2015): 324-342. 
11. Stanujkic, Dragisa, Nedeljko Magdalinovic, Rodoljub Jovanovic, and Sanja Stojanovic. "An objective multi-criteria approach to optimization using MOORA method and interval grey numbers." Technological and Economic Development of Economy 18, no. 2 (2012): 331-363.

12. Khan, Akhtar, and K. P. Maity. "Parametric optimization of some non-conventional machining processes using MOORA method." In International journal of engineering research in Africa, vol. 20, pp. 19-40. Trans Tech Publications Ltd, 2016.

13. Ic, Yusuf Tansel. "A multi-objective credit evaluation model using MOORA method and goal programming." Arabian Journal for Science and Engineering 45, no. 3 (2020): 2035-2048.

14. Pathapalli, Venkateshwar Reddy, Veerabhadra Reddy Basam, Suresh Kumar Gudimetta, and Madhava Reddy Koppula. "Optimization of machining parameters using WASPAS and MOORA." World Journal of Engineering (2019).

15. Jain, Vineet. "Application of combined MADM methods as MOORA and PSI for ranking of FMS performance factors." Benchmarking: an international journal (2018).

16. Brauers, Willem Karel M. "Multi-objective contractor's ranking by applying the MOORA method." Journal of Business Economics and management 4 (2008): 245-255.

17. Jayant, Arvind, Aditya Kumar Chandan, and Shweta Singh. "Sustainable supplier selection for battery manufacturing industry: A MOORA and WASPAS Based Approach." In Journal of Physics: Conference Series, vol. 1240, no. 1, p. 012015. IOP Publishing, 2019.

18. Sahu, Anoop Kumar, Nitin Kumar Sahu, and Atul Kumar Sahu. "Appraisal of CNC machine tool by integrated MULTI-MOORA-IVGN circumferences: An empirical study." Grey Systems: Theory and Application (2014).

19. Causa, Hon, and Willem KM Brauers. "Location of a seaport by MOORA optimization." In 2014 International Conference on Advanced Logistics and Transport (ICALT), pp. 275-280. IEEE, 2014.

20. Brauers, Willem Karel M., Romualdas Ginevičius, and Valentinas Podvezko. "Regional development in Lithuania considering multiple objectives by the MOORA method." Technological and Economic Development of Economy 16, no. 4 (2010): 613-640.

21. Brauers, Willem Karel M. "Multi-objective seaport planning by MOORA decision making." Annals of Operations Research 206, no. 1 (2013): 39-58.

22. Sahu, Anoop Kumar, Nitin Kumar Sahu, and Atul Kumar Sahu. "Application of modified MULTI-MOORA for CNC machine tool evaluation in IVGTFNS environment: an empirical study." International Journal of Computer Aided Engineering and Technology 8, no. 3 (2016): 234-259.

23. Mavi, Reza Kiani, Mark Goh, and Navid Zarbakhshnia. "Sustainable third-party reverse logistic provider selection with fuzzy SWARA and fuzzy MOORA in plastic industry." The International Journal of Advanced Manufacturing Technology 91, no. 5 (2017): 2401-2418.

24. Büyüközkan, Gülçin, and Fethullah Göçer. "An extension of MOORA approach for group decision making based on interval valued intuitionistic fuzzy numbers in digital supply chain." In 2017 Joint 17th world congress of international fuzzy systems association and 9th international conference on soft computing and intelligent systems (IFSA-SCIS), pp. 1-6. IEEE, 2017.

25. Tamrin, K. F., and A. Y. Zahrim. "Determination of optimum polymeric coagulant in palm oil mill effluent coagulation using multiple-objective optimisation on the basis of ratio analysis (MOORA)." Environmental Science and Pollution Research 24, no. 19 (2017): 15863-15869.

26. Das, Manik Chandra, Bijan Sarkar, and Siddhartha Ray. "Comparative evaluation of Indian technical institutions using fuzzy AHP and MOORA." International Journal of Multicriteria Decision Making 2, no. 1 (2012): 74-93.

27. Awathankar, Rahul V., M. S. S. Rukmini, and Rajeshree D. Raut. "To mitigate with trusted channel selection using MOORA algorithm in cognitive radio network." Iranian Journal of Science and Technology, Transactions of Electrical Engineering 45, no. 2 (2021): 381-390.

28. Lubis, Ahmadi Irmansyah, Poltak Sihombing, and Erna Budhiarti Nababan. "Comparison SAW and MOORA Methods with Attribute Weighting Using Rank Order Centroid in Decision Making." In 2020 3rd International Conference on Mechanical, Electronics, Computer, and Industrial Technology (MECnIT), pp. 127-131. IEEE, 2020.

29. Sakti, Chosy Yuda, Kelly Rossa Sungkono, and Riyanarto Sarno. "Determination of Hospital Rank by Using Analytic Hierarchy Process (AHP) and Multi Objective Optimization on the Basis of Ratio Analysis (MOORA)." In 2019 International Seminar on Application for Technology of Information and Communication (iSemantic), pp. 178-183. IEEE, 2019.

30. Abhang, Laxman B., Mohd Iqbal, and M. Hameedullah. "Optimization of machining process parameters using moora method." In Defect and Diffusion Forum, vol. 402, pp. 81-89. Trans Tech Publications Ltd, 2020.

31. Dr. Amol Lokhande, Dr. C. Venkateswaran, Dr. M. Ramachandran, C. Sathiyaraj, K. Nathiya, Recycling Process Impact in Current Scenario Manufacturing: A Study, Recent trends in Management and Commerce Vol: 2(1), 2021, 20-25.

32. Gadde Mehar Chaitanya, M.P.Jenarthanan, C. Sathiyaraj, A Review on Glass fibre Reinforced Composites with Different Matrix, REST Journal on Emerging trends in Modelling and Manufacturing Vol: 7(1), 2021, 18-24.

33. R. Kurinjimalar, S. Vimala, M. Silambarasan, S. Chinnasami, A Review on Coir fibre Reinforced Composites with Different Matrix, REST Journal on Emerging trends in Modelling and Manufacturing Vol: 7(2), 2021, 25-32.

34. P. K. Chidambaram, Dr. Amol Lokhande, Dr. M. Ramachandran, Vimala Saravanan, Vidhya Prasanth, A Review on Biodiesel Properties and Fatty acid composites, REST Journal on Emerging trends in Modelling andManufacturing Vol: 7(3), 2021, 87-93. 
35. P.K.Chidambaram, Dr. Amol Lokhande, Dr. M. Ramachandran, M. Nathiya, G. Mathivanan, A study on Carbon Fiber Based Polymer Rein Force composites, REST Journal on Emerging trends in Modelling andManufacturing Vol: 7(3), 2021, 94-100.

36. Kshirsagar, Pravin, and Sudhir G. Akojwar. "Chaotic Time Series Prediction using Correlation Dimension and Adaptive Neuro-Fuzzy Inference System."

37. Sundaramurthy, Shanmugam, C. Saravanabhavan, and Pravin Kshirsagar. "Prediction and Classification of Rheumatoid Arthritis using Ensemble Machine Learning Approaches." In 2020 International Conference on Decision Aid Sciences and Application (DASA), pp. 17-21. IEEE, 2020.

38. Kshirsagar, Pravin, Rajesh Sondrikar, Ashwini Dhandole, Harsha Nehare, and Ashish Thakare. "Interactive Voice Response System with Portable Wi-Fi Calling."

39. Deshmukh, Vivek, and Pravin Kshirsagar. "Recognition of Front and Rear Tyres Using Stationary Wavelet Transform for Car Manufacturing." (2012).

40. Tafhim, M. O. H. A. M. M. A. D., and P. R. A. V. I. N. Kshirsagar. "A Review on EMG Signal Classification for neurological disorder using neural network." In International conference on Advances in Engineering \& Technology2014 (ICAET-2014), pp. 21-23. 2014.

41. Kshirsagar, Pravin, Ambarish Salodkar, and Roshan Bhaiswar. "Generic Approach in Automation and Sensors for Enhanced Efficiency." International Journal of Emerging Technology and Advanced Engineering 2, no. 3 (2012): $152-156$

42. Kshirsagar, Pravin R., Arpit D. Yadav, Kirti A. Joshi, Pranav Chippalkatti, and Rinali Y. Nerkar. "Classification and Detection of Brain Tumor by using GLCM Texture Feature and ANFIS." Journal of Research in Image and Signal Processing 5, no. 1 (2020): 15-31.

43. Umapathi, and Ramaraj. "PERFORMANCE EVALUATION OF DSR ROUTING PROTOCOL UNDER DIVERGING AND CONVERGING NODES." IIOAB JOURNAL 7, no. 9 (2016): 269-275.

44. Umapathi, N., and N. Ramaraj. "Wireless Adhoc Telemedicine System: Improving Network Performance for Multimedia Data." Journal of Medical Imaging and Health Informatics 6, no. 8 (2016): 1944-1948.

45. Krishna, G. Murali, G. Karthick, and N. Umapathi. "Design of Dynamic Comparator for Low-Power and High-Speed Applications." In ICCCE 2020, pp. 1187-1197. Springer, Singapore, 2021.

46. Umapathi, N., G. Murali Krishna, and Lingala Srinivas. "A Comprehensive Survey on Distinctive Implementations of Carry Select Adder." In 2021 4th Biennial International Conference on Nascent Technologies in Engineering (ICNTE), pp. 1-5. IEEE, 2021.

47. Umapathi, N., Saiteja Sabbani, and S. Poovarasan. "Person Location Tracking Using Global Positioning System and ESP8266 with Internet of Things." In Futuristic Communication and Network Technologies, pp. 211-217. Springer, Singapore, 2022.

48. Umapathi, N., and Saiteja Sabbani. "An Internet of Things (IoT)-based Approach for Real-Time Kitchen Monitoring Using NodeMCU 1.0." In Futuristic Communication and Network Technologies, pp. 35-43. Springer, Singapore, 2022.

49. Balaji, V., V. Duraisamy, and N. Umapathi. "Cluster based packet loss prediction using packet lost segment in wireless network." In 2010 IEEE International Conference on Computational Intelligence and Computing Research, pp. 1-4. IEEE, 2010.

50. Balaji, V., V. Duraisamy, and N. Umapathi. "Cluster based packet loss prediction using packet lost segment in wireless network." In 2010 IEEE International Conference on Computational Intelligence and Computing Research, pp. 1-4. IEEE, 2010.

51. Umapathi, N., Sai Teja, and Sai Kiran. "Design and Implementation of Prevent Gas Poisoning from Sewage Workers using Arduino." In 2020 IEEE International Symposium on Sustainable Energy, Signal Processing and Cyber Security (iSSSC), pp. 1-4. IEEE, 2020.

52. Bharathy, AM Viswa, N. Umapathi, and S. Prabaharan. "An Elaborate Comprehensive Survey on Recent Developments in Behaviour Based Intrusion Detection Systems." In 2019 International Conference on Computational Intelligence in Data Science (ICCIDS), pp. 1-5. IEEE, 2019.

53. Balaji, V., N. Umapathy, V. Duraisamy, K. Umapathy, P. Venkatesan, and S. Saravanakumar. "ENHANCING VARYING OVERHEAD AD HOC ON DEMAND DISTANCE VECTOR WITH ARTIFICIAL ANTS." Jurnal Teknologi 77, no. 28 (2015).

54. Umapathi, N., N. Ramaraj, and R. Adlin Mano. "A proactive ant colony algorithm for efficient power routing using MANET." International Journal of Computer Applications 58, no. 20 (2012).

55. Dhaarani, S. D., Sona Ponnuswamy, and Manashree Mane. "A Study on Impact of Pellets on Different Targets-A Preliminary Study." Medico-Legal Update 21, no. 4 (2021).

56. Katakam, Lakshmi Narasimha Rao, Thirupathi Dongala, and Santhosh Kumar Ettaboina. "Novel stability indicating UHPLC method development and validation for simultaneous quantification of hydrocortisone acetate, pramoxine hydrochloride, potassium sorbate and sorbic acid in topical cream formulation." Talanta Open 1 (2020): 100004.

57. Dongala, Thirupathi, Naresh Kumar Katari, Santhosh Kumar Ettaboina, Anand Krishnan, Murtaza M. Tambuwala, and Kamal Dua. "In vitro Dissolution Profile at Different Biological pH Conditions of Hydroxychloroquine Sulfate Tablets Is Available for the Treatment of COVID-19." Frontiers in Molecular Biosciences 7 (2021): 441.

58. Katakam, Lakshmi Narasimha Rao, Santhosh Kumar Ettaboina, and Thirupathi Dongala. "A simple and rapid HPLC method for determination of parabens and their degradation products in pharmaceutical dosage forms." Biomedical Chromatography (2021): e5152. 
59. Katakam, Lakshmi Narasimha Rao, Thirupathi Dongala, and Santhosh Kumar Ettaboina. "Quality by design with design of experiments approach for development of a stability-indicating LC method for enzalutamide and its impurities in soft gel dosage formulation." Biomedical Chromatography 35, no. 5 (2021): e5062.

60. Yenda, Parvateesam, Naresh Kumar Katari, Thirupathi Dongala, Govind Vyas, Lakshmi Narasimha Rao Katakam, and Santhosh Kumar Ettaboina. "A simple isocratic LC method for quantification of trace-level inorganic degradation impurities (ferricyanide, ferrocyanide, nitrite, and nitrate) in sodium nitroprusside injection and robustness by quality using design approach." Biomedical Chromatography (2021): e5269.

61. Katakam, Lakshmi Narasimha Rao, Santhosh Kumar Ettaboina, and Vishnu Murthy Marisetti. "Development and validation of LC-MS method for the determination of heptaethylene glycol monomethyl ether in benzonatate bulk drugs." Biomedical Chromatography 35, no. 7 (2021): e5096.

62. DHEENADHAYALAN, V. "Impact Of Training And Development On Performance Appraisal Of Employees In Information Technology Companies A Study With Reference To Chennai City."

63. Dheenadhayalan, V. "Mudra-A Tool for Uplifting Micro Enterprises in India." International Journal in Management \& Social Science 4, no. 12 (2016): 235-246.

64. Dheenadhayalan, V., and R. Devianbarasi. "Relationship between liquidity and profitability-a case study of NPKRR cooperative sugar mill ltd." Indian Cooperative Review 47, no. 1 (2009): 39-46.

65. DEY, SUMIT, LAKHIMI NATH, and PRIYAM KALITA. "Self Help Group-Bank Linkage Programme as an Instrument of Economic Upliftment of Poor Women of Assam: A case Study of Raha Block of Nagaon District." REQUEST FOR FEEDBACK \& DISCLAIMER 76 (2014).

66. Dheenadhayalan, Kalpana Devi K. Dr V. "TRAINING NEED ANALYSIS OF EMPLOYEES IN IT COMPANIES." From the Editor's Desk: 76.

67. Shahid, Amita, and Taptej Singh. "Pradhan Mantri Jan Dhan Yojana: A vehicle for financial inclusion." Indian Journal of Economics and Development 11, no. 2 (2015): 499-508.

68. Banana, K. R. I. S. H. N. A., and R. V. Chepuri. "Role of recovery channels in managing non-performing assets in scheduled commercial banks." International Journal for Innovative Research in Multidisciplinary Field 2, no. 10 (2016):355-359.

69. Chaudhari, Rakesh, and Asha Ingle. "Finite Element Analysis of Dissimilar Metal Weld of SA335 P11 and SA312 TP304 Formed By Transition Grading Technique." Materials Today: Proceedings 5, no. 2 (2018): 7972-7980.

70. Tibadia, Rajkumar, Koustubh Patwardhan, Dhrumil Patel, Dinesh Shinde, and Rakesh Chaudhari. "Optimisation of drilling parameters for minimum circularity error in FRP composite." International Journal of Materials Engineering Innovation 10, no. 4 (2019): 271-285.

71. Patil, Niteen, M. R. Patil, Rakesh Chaudhari, and Praveen Kumar Loharkar. "Investigation on the Machining of Inconel-718 Using EDM." In Recent Advances in Smart Manufacturing and Materials, pp. 129-136. Springer, Singapore, 2021.

72. Chaudhari, Rakesh, Praveen Kumar Loharkar, and Asha Ingle. "Medical Applications of Rapid Prototyping Technology." In Recent Advances in Industrial Production, pp. 241-250. Springer, Singapore, 2022.

73. Chaudhari, Rakesh, Asha Ingle, and Kanak Kalita. "Experimental Investigation of Correlation of Grain Size and Mechanical Properties in 304 Stainless Steel." Materials Focus 5, no. 5 (2016): 440-445.

74. Chaudhari, R., P. K. Loharkar, and A. Ingle. "Applications and challenges of arc welding methods in dissimilar metal joining." In IOP Conference Series: Materials Science and Engineering, vol. 810, no. 1, p. 012006. IOP Publishing, 2020.

75. Chaudhari, Rakesh, Asha Ingle, and Kanak Kalita. "Tribological Investigation of Effect of Grain Size in 304 Austenitic Stainless Steel." Transactions of the Indian Institute of Metals 70, no. 9 (2017): 2399-2405.

76. Chaudhari, Rakesh, and Asha Ingle. "Experimental investigation of dissimilar metal weld of SA335 P11 and SA312 TP304 formed by gas tungsten arc welding (GTAW)." Transactions of the Indian Institute of Metals 72, no. 5 (2019): $1145-1152$.

77. Kittur, Jeevan, Bhavya Desai, Rakesh Chaudhari, and Praveen Kumar Loharkar. "A comparative study of EMI shielding effectiveness of metals, metal coatings and carbon-based materials." In IOP Conference Series: Materials Science and Engineering, vol. 810, no. 1, p. 012019. IOP Publishing, 2020.

78. Chaudhari, Rakesh, Asha Ingle, and Kanak Kalita. "Stress analysis of dissimilar metal weld between carbon steel and stainless steel formed by transition grading technique." Materials Today: Proceedings 2, no. 4-5 (2015): 1657-1664.

79. Kalita, Kanak, Rakesh Chaudhari, and M. Ramachandran. "Mechanical characterization and finite element investigation on properties of PLA-jute composite." International Journal of Computer Applications 123, no. 13 (2015).

80. Tibadia, Rajkumar, Koustubh Patwardhan, Dhrumil Shah, Dinesh Shinde, Rakesh Chaudhari, and Kanak Kalita. "Experimental investigation on hole quality in drilling of composite pipes." Transactions of the Canadian Society for Mechanical Engineering 42, no. 2 (2018): 147-155. 